\title{
Téoros
}

Revue de recherche en tourisme

\section{La relation tourisme-ruralité}

\section{Laurent Bourdeau}

Volume 20, numéro 2, été 2001

Tourisme rural

URI : https://id.erudit.org/iderudit/1071635ar

DOI : https://doi.org/10.7202/1071635ar

Aller au sommaire du numéro

\section{Éditeur(s)}

Université du Québec à Montréal

ISSN

0712-8657 (imprimé)

1923-2705 (numérique)

Découvrir la revue

Citer ce document

Bourdeau, L. (2001). La relation tourisme-ruralité. Téoros, 20(2), 3-3.

https://doi.org/10.7202/1071635ar d'utilisation que vous pouvez consulter en ligne.

https://apropos.erudit.org/fr/usagers/politique-dutilisation/ 


\section{Présentation}

\section{La relation tourisme-ruralité}

\section{Laurent Bourdeau}

Rédacteur invité

V ivant généralement en régions urbaines, les touristes en milieu rural cherchent à vivre une expérience exotique et différente de leur quotidien. Les sensations recherchées, bien qu'éloignées de celles ressenties dans leur environnement urbain, sont en de nombreux cas liées à leurs habitudes de vie. L'exemple le plus saillant se trouve dans la relation entre les produits alimentaires consommés à la ville et les lieux de production de ces mêmes aliments. Par l'expérience agrotouristique, les touristes passent de la table à la terre, de la ville à la campagne, découvrent les racines et les différences qui composent un pays.

Ce retour momentané à la terre pratiqué lors des activités touristiques en milieu rural pourrait représenter un nouvel appel à la non-standardisation. Non seulement le touriste est-il à la quête d'exotisme grâce à ses visites en milieu rural, mais il cherche également à découvrir des régions différentes qui offrent des paysages, des produits, des sensations et des individus différents.

Bien que des études portant sur l'agrotourisme et le tourisme en milieu rural tendent à démontrer qu'un nombre important de touristes proviennent des milieux urbains, il ne faudrait pas négliger la présence des paysans parmi la clientèle touristique. Que ce soit comme excursionniste ou comme touriste étranger, des clientèles provenant des milieux ruraux pratiquent aussi l'agrotourisme ou visitent également des milieux ruraux pendant leurs vacances. Ce phénomène est notamment observé sur le plan des clientèles internationales. Par contre, nous ne connaissons encore que peu de choses sur le comportement de ces touristes et ce, particulièrement au Québec.

Phénomène encore marginal, mais en plein développement, l'agrotourisme est souvent confondu avec la pratique du tourisme en milieu rural. L'agrotourisme ou l'agritourisme représente souvent pour la profession agricole une source de diversification des revenus, alors qu'il représente pour le touriste une occasion de rencontrer directement le producteur dans son milieu. Le touriste peut alors trouver des produits qu'il ne peut avoir chez lui ou encore découvrir le lieu de production de produits qu'il consomme dans son environnement urbain. Le tourisme en milieu rural peut quant à lui être défini par la pratique de toutes les formes touristiques en milieu rural. En conséquence, l'agrotourisme ou l'agritourisme fait partie du système touristique en milieu rural.

Le présent numéro de Téoros apporte un éclairage nouveau sur la pratique du tourisme en milieu rural et l'agrotourisme. Par opposition à la vision où le tourisme est présenté comme une panacée économique pour les régions rurales, ce numéro de Téoros cherche à situer le rôle du tourisme comme outil de développement économique et social des régions rurales. L'établissement de ce lien entre le monde touristique et le monde agricole est notamment démontré par le fait que le tourisme en milieu rural est tributaire, dans une très large mesure, du territoire agricole et de ses caractéristiques.

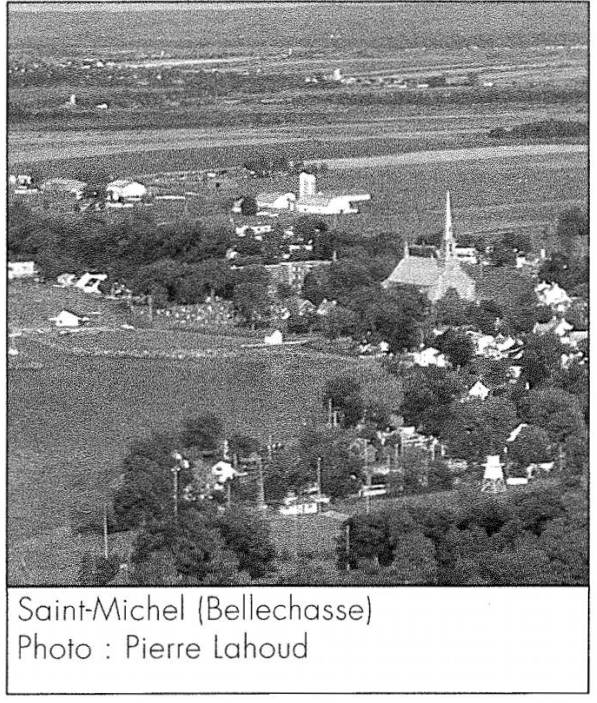

Au cours des dernières années, nous avons assisté à de nombreux efforts de concertation de la part des milieux agroalimentaires, ruraux et touristiques. Les colloques et les rencontres sur l'agrotourisme en sont une preuve. Par contre, il y a encore place à la réflexion sur les pratiques touristiques en milieu agricole, mais aussi sur les pratiques agricoles qui ne prennent pas toujours en compte le développement d'une industrie touristique en territoire agricole. En ce sens, le présent numéro de Téoros représente une contribution à cette réflexion sur deux milieux qui évoluent parfois de façon parallèle.

Laurent Bourdeau, docteur en marketing (Ph.D.), enseigne le marketing en tourisme et il est directeur du certificat en gestion du développement touristique. Outre sa carrière de professeur, il est membre du Groupe de recherche en tourisme à l'Université Laval. 